\title{
A Case With Vitamin D Deficiency-Induced Cytomegalovirus Enteritis Presenting as Bowel Pseudo-Obstruction
}

\author{
Shou-Wu Lee ${ }^{\mathrm{a}, ~ b, ~ d}$, Chung-Wang Ko ${ }^{\mathrm{a}, ~ c}$, Szu-Chia Liao ${ }^{\mathrm{a}}$, Chung-Shihn Chang ${ }^{\mathrm{a}}$, \\ Hong-Zen Yeh ${ }^{\mathrm{a}, \mathrm{c}}$, Chi-Sen Chang ${ }^{\mathrm{a}, \mathrm{b}}$
}

\begin{abstract}
Cytomegalovirus (CMV) infection in small intestines has rarely been reported. We report a 67-year-old woman with abdominal pain for 2 weeks. Abdominal computed tomography (CT) revealed wall-thickening of the segmental small bowel. Enteroscopy disclosed discrete ulcers at the jejunum, and biopsy histopathology showed positive CMV immunoreactivity. Laboratory tests showed positive blood CMV with a viral load of 9,400 DNA copies/mL and high IgG titer and low vitamin D level. After antiviral therapy and oral vitamin D supply, her symptoms improved. Follow-up CT and enterology showed resolved enteritis.
\end{abstract}

Keywords: Cytomegalovirus; Enteritis; Vitamin D deficiency

\section{Introduction}

Cytomegalovirus (CMV) infection is often due to the reactivation of latent disease in immunosuppressed and in some critically ill immunocompetent patients [1]. While involving the gastrointestinal tract, the site most commonly affected is the colon, followed by the duodenum, stomach, esophagus and small intestine [2]. Vitamin D, measured as 25-OH-D3, has emerged as a central player in the immune system, and deficiency of vitamin D carries a risk factor of infections [3]. We report a case of CMV jejunitis in a 67-year-old woman who had low vitamin D level and presented with a sign of bowel

Manuscript submitted March 10, 2017, accepted April 03, 2017

aDivision of Gastroenterology, Department of Internal Medicine, Taichung Veterans General Hospital, Taichung, Taiwan, Republic of China

${ }^{b}$ Department of Internal Medicine, Chung Shan Medical University, Taichung, Taiwan, Republic of China

'Department of Internal Medicine, National Yang-Ming University School of Medicine, Taipei, Taiwan, Republic of China

${ }^{\mathrm{d}}$ Corresponding Author: Shou-Wu Lee, Division of Gastroenterology, Department of Internal Medicine, Taichung Veterans General Hospital, Taichung, 1650 Taiwan Boulevard, Sec. 4, Taichung 40705, Taiwan, Repblic of China. Email: ericest@vghtc.gov.tw

doi: https://doi.org/10.14740/gr823w pseudo-obstruction.

\section{Case Report}

A 67-year-old woman without underlying disease was referred to our hospital due to abdominal pain and less stool passage for 2 weeks. She did not have a history of abdominal surgeries, and she reported no fever, melena or body weight loss. The physical examination revealed a distended abdomen with hypoactive bowel sound. Laboratory studies showed low hemoglobin of $9.0 \mathrm{~g} / \mathrm{dL}$ (normal, $11.3-15.3 \mathrm{~g} / \mathrm{dL}$ ), low calcium of $6.0 \mathrm{mg} / \mathrm{dL}$ (normal, $8.4-10.2 \mathrm{mg} / \mathrm{dL}$ ), high C-reactive protein (CRP) of $3.3 \mathrm{mg} / \mathrm{dL}$ (normal, $<0.5 \mathrm{mg} / \mathrm{dL}$ ), normal creatine of $0.4 \mathrm{mg} / \mathrm{dL}$ (normal, $0.6-1.2 \mathrm{mg} / \mathrm{dL}$ ), normal sodium of 139 $\mathrm{mg} / \mathrm{dL}$ (normal, $137-153 \mathrm{mg} / \mathrm{dL}$ ), normal potassium of 4.4 $\mathrm{mg} / \mathrm{dL}$ (normal, 3.5 - $5.3 \mathrm{mg} / \mathrm{dL}$ ), normal alanine aminotransferase (ALT) of $13 \mathrm{U} / \mathrm{L}$ (normal, 8 - $38 \mathrm{U} / \mathrm{L}$ ), normal alkaline phosphatase (ALP) of $65 \mathrm{U} / \mathrm{L}$ (normal, 50 - $190 \mathrm{U} / \mathrm{L}$ ), normal free $\mathrm{T} 4$ of $16.9 \mathrm{pg} / \mathrm{mL}$ (normal $8.9-17.6 \mathrm{pg} / \mathrm{mL}$ ), normal thyroid-stimulating hormone (TSH) of $1.26 \mu \mathrm{IU} / \mathrm{mL}$ (normal, 0.4 - $4.0 \mu \mathrm{IU} / \mathrm{mL}$ ), and negative anti-nuclear antibody (ANA), human immunodeficiency virus (HIV), and hepatitis B or C. Further survey for hypocalcemia revealed high parathyroid hormone (PTH) of $105 \mathrm{pg} / \mathrm{mL}$ (normal, $12-65 \mathrm{pg} / \mathrm{mL}$ ) and lowe $25-\mathrm{OH}-\mathrm{D} 3$ of $3.8 \mathrm{mg} / \mathrm{mL}$ (normal, $5-30 \mathrm{ng} / \mathrm{mL}$ ).

Contrast-enhanced abdominal computed tomography (CT) revealed wall-thickening and prominent enhancement of the segmental small bowel (Fig. 1a). Esophagogastroduodenoscopy and colonscopy did not identify specific findings. Support care was adopted initially, but her symptoms persisted. Push-type enteroscopy (Olympus SIF-100, Hamburg, Germany) was performed and disclosed hyperemic mucosal change with discrete ulcers extending from the upper to the middle jejunum (Fig. 1b). Biopsy histopathology showed inflammatory cell infiltration with positive CMV immunoreactivity (Fig. 2). CMV viral load was 9,400 DNA copies/mL, and serum CMV IgG titer was as high as 7.407 (normal $<0.8$ ). Antiviraltherapy with ganciclovir ( $250 \mathrm{mg}$ every $12 \mathrm{~h}$ ) for 14 days was prescribed, followed by oral valganciclovir $(900 \mathrm{mg} /$ day) for 1 month. Oral vitamine D was also prescribed. Her abdominal pain subsided gradually. Follow-up abdominal CT and enteroscopy 2 months later found resolved bowel wall-thickening and healed ulcers over the jejunum (Fig. 3a, b). The labora- 


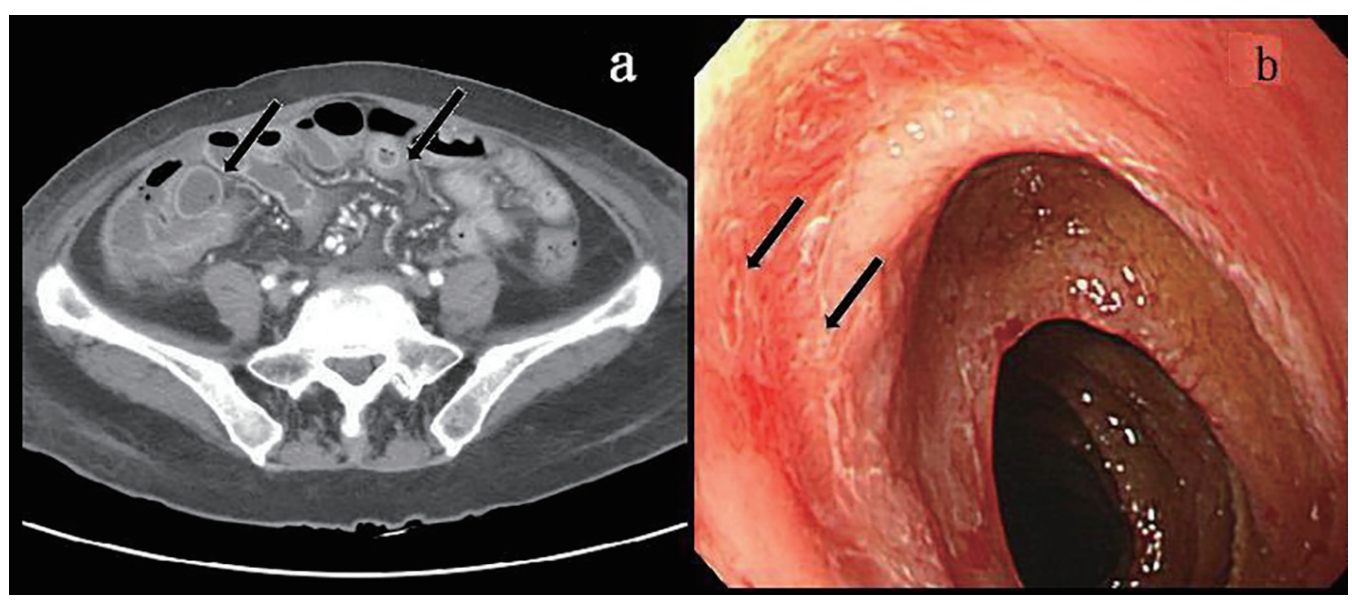

Figure 1. Pre-treatment contrast-enhanced abdominal CT showed wall-thickening of the segmental small bowel (arrow) (a), and pre-treatment enteroscopy showed hyperemic mucosal change with discrete ulcers (arrow) at the jejunum (b).

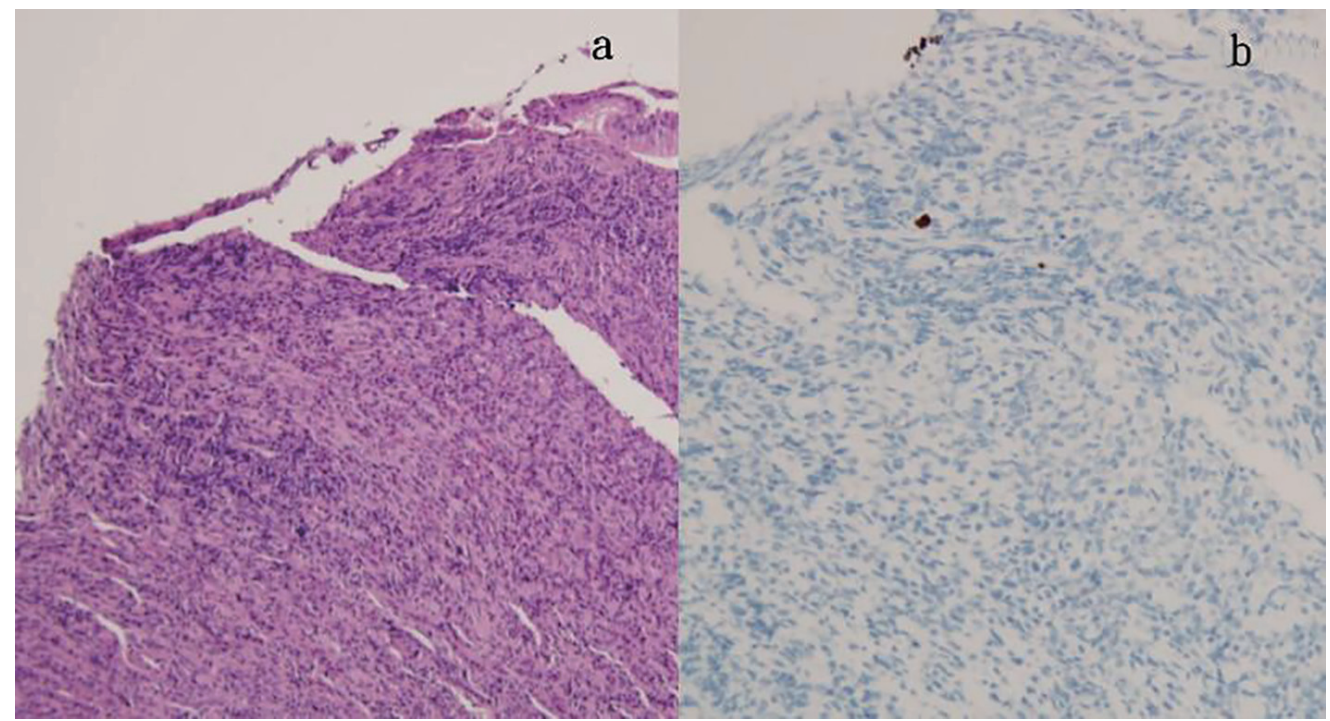

Figure 2. Biopsy of jejunal mucosa showed ulceration, chronic active inflammation (a, H\&E stain), and cytomegaloviral infected cells as revealed by immunohistochemistry (b).

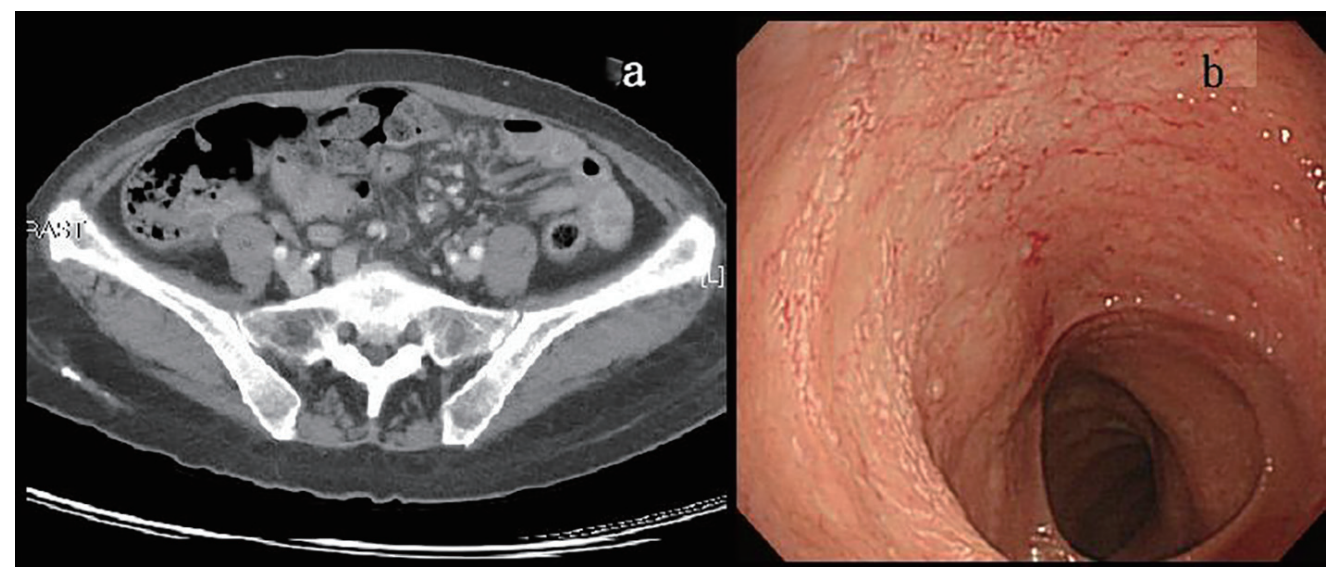

Figure 3. Post-treatment contrast-enhanced abdominal CT showed resolved bowel wall-thickening (arrow) (a), and post-treatment enteroscopy showed healed ulcers (arrow) at the jejunum (b). 
tory data 2 months later revealed undetectable CMV viral load, CMV IgG titer, and normal level of 25-OH-D3.

\section{Discussion}

In CMV infection of the gastrointestinal tract, the site most commonly affected is the colon $(47 \%)$, followed by the duodenum $(21.7 \%)$, stomach $(17.4 \%)$, esophagus $(8.7 \%)$ and small bowel (4.3\%) [4]. Endoscopic characteristics of CMV colitis included heterogeneous ulcerative pattern, inflammatory process of the mucosa, or normal mucosa [5]. Besides, CMV enterocolitis can also present with pseudo-tumor formation [6]. Symptoms and signs of gastrointestinal CMV infection include abdominal pain, watery or bloody diarrhea, per rectum bleeding, obstruction, perforation and fistula formation [7]. In our case, CMV infection in the jejunum caused signs of small bowel pseudo-obstruction, and it improved after antiviral therapy.

CMV may infect various gastrointestinal cells, including the vascular endothelial cells and stromal fibroblasts. CMV infection in the vascular endothelial cells leads to abnormal cellular swelling and enlargement, vascular luminal compromise, fibrin thrombus formation, local vasculitis and tissue damage in the intestinal segment supplied by the affected vessels. The severity and outcome of CMV enteritis depends on the host's immune status. Risk factors include acquired immune deficiency syndrome (AIDS), organ recipients, immunosuppression, hematological malignancies or chemotherapy [8]. The early diagnosis of CMV enteritis and apparent antiviral therapy to the patients with risk factors are necessary.

Vitamin D has a critical role in the immune system, affecting T and B cells, macrophages and dendritic cells [9]. Vitamin D deficiency was reported associated with disorders of the immune system, such as multiple sclerosis, type 1 diabetes, rheumatoid arthritis and rejection of solid organ allografts [3]. Vitamin D also has a protective effect against infections. The two antimicrobial peptides under the influence of vitamin D are LL-37 (cathelicidin) and $\beta$-defensin 2 , which have activity against several bacteria, as well as viruses and fungi [10]. One retrospective cohort analysis of 166 patients who underwent allogeneic hematopoietic stem cell transplantation found that low vitamin D levels represent a significant risk factor for CMV disease [3].

In conclusion, we reported a case of CMV enteritis in a 67-year-old woman who had vitamin D deficiency and presented with small bowel pseudo-obstruction. CMV enteritis should be included in the list of differential diagnoses when observing enteritis and a persistent sign of small bowel obstruction.

\section{References}

1. Sandkovsky U, Florescu DF, Um JY, Raichlin E, Lowes BD, Kapalis M, Hewlett A, et al. Cytomegalovirus reactivation and colitis after left ventricular assist device placement. Int J Infect Dis. 2013;17(5):e348-351.

2. Goodgame RW. Gastrointestinal cytomegalovirus disease. Ann Intern Med. 1993;119(9):924-935.

3. von Bahr L, Blennow O, Alm J, Bjorklund A, Malmberg $\mathrm{KJ}$, Mougiakakos D, Le Blanc A, et al. Increased incidence of chronic GvHD and CMV disease in patients with vitamin $\mathrm{D}$ deficiency before allogeneic stem cell transplantation. Bone Marrow Transplant. 2015;50(9):12171223.

4. Hinnant KL, Rotterdam HZ, Bell ET, Tapper ML. Cytomegalovirus infection of the alimentary tract: a clinicopathological correlation. Am J Gastroenterol. 1986;81(10):944-950.

5. Marques O Jr, Averbach M, Zanoni EC, Correa PA, Pac$\cos$ JL, Cutait R. Cytomegaloviral colitis in HIV positive patients: endoscopic findings. Arq Gastroenterol. 2007;44(4):315-319.

6. You DM, Johnson MD. Cytomegalovirus infection and the gastrointestinal tract. Curr Gastroenterol Rep. 2012;14(4):334-342.

7. Buckner FS, Pomeroy C. Cytomegalovirus disease of the gastrointestinal tract in patients without AIDS. Clin Infect Dis. 1993;17(4):644-656.

8. Vancikova Z, Dvorak P. Cytomegalovirus infection in immunocompetent and immunocompromised individuals - a review. Curr Drug Targets Immune Endocr Metabol Disord. 2001;1(2):179-187.

9. Maruotti N, Cantatore FP. Vitamin D and the immune system. J Rheumatol. 2010;37(3):491-495.

10. Wang TT, Nestel FP, Bourdeau V, Nagai Y, Wang Q, Liao J, Tavera-Mendoza L, et al. Cutting edge: 1,25-dihydroxyvitamin D3 is a direct inducer of antimicrobial peptide gene expression. J Immunol. 2004;173(5):2909-2912. 